\title{
Practices and knowledge of female gynecologists regarding contraceptive use: a real-world Chinese survey
}

\author{
Xin Yang ${ }^{1 *}$, Xiaodong $\mathrm{Li}^{2}$, Yanjie Wang ${ }^{1}$, Xiaojing $\mathrm{He}^{2}$ and Yang Zhao ${ }^{1}$
}

\begin{abstract}
Background: There is no evidence of the practices of obstetricians and gynecologists (OB/GYNs) regarding contraceptive use and determinants influencing contraceptive choices, including emergency methods such as combined oral contraceptives (COCs) and levonorgestrel intrauterine system (LNGIUS). This survey determines the practices and knowledge among Chinese female OB/GYNs regarding modern contraceptive methods.

Methods: A multicenter questionnaire was completed by 2000 female OB/GYNs participating in training courses organized by the gynecological endocrinology training committee of the Chinese Medical Doctor Association from February to May 2013.

Results: This survey achieved a response rate of $51.4 \%$. The rate of induced abortion among this group was $56.3 \%$; this may be attributable to unreliable contraceptive methods (55.5\%) and failure of reliable contraceptive methods (18.9\%). Intrauterine devices (IUDs) were more commonly used by parous women than nulliparous women (42.6\% vs 1.7\%; $p<0.0001$ ), followed by condom and rhythm method (24.2\% vs $20.8 \%$ ). However, nulliparous women commonly used rhythm method (48.3\% vs $3.3 \% ; p<0.0001)$ and condoms (19.2\% vs $10.5 \% ; p=0.008)$. $\mathrm{OB} / \mathrm{GYNs}$ demonstrated misconceptions of OB/GYNs about COCs, such as the risk of breast cancer, amenorrhea and premature ovarian failure, and decreased fertility as reported by $37.10,10.6$, and $7.5 \%$ of the respondents, respectively.

Conclusions: IUDs were commonly used by parous Chinese OB/GYNs. Unreliable contraceptive methods and misconceptions about the side effects of COCs may result in the high rate of unintended pregnancies. Hence, awareness of safe and effective contraceptive methods should be strengthened among OB/GYNs in China.
\end{abstract}

Keywords: Contraception, Knowledge and personal choice, Female obstetricians/gynecologists, Combined oral contraceptives

\section{Plain text summary}

Obstetricians and gynecologists (OB/GYNs) play a major role in counselling and guiding patients on contraceptive use. They should be well aware of the benefits and risks of different contraceptives. To date, there is no evidence on the knowledge and practices of OB/GYNs regarding contraceptive use and factors influencing their contraceptive choices.

\footnotetext{
* Correspondence: Xinyang_2003@sina.com

'Department of Obstetrics and Gynecology, Peking University People's

Hospital, Xicheng District, Beijing 100044, China

Full list of author information is available at the end of the article
}

The current study was designed to determine the knowledge and contraceptive practices among OB/GYNs of reproductive age. $51.4 \%$ of 2000 of OB/GYNs responded to the survey. The rate of abortion was found to be $56.3 \%$, which was reportedly due to unreliable contraceptive methods (55.5\%) and failure of reliable contraceptive methods (18.9\%). Intrauterine devices (IUDs) were more commonly used by parous women $(42.6 \%$ vs $1.7 \% ; p<0.0001)$ followed by Condoms and the rhythm method $(24.2 \%$ vs $20.8 \%)$ compared to nulliparous women. However, women without children more commonly used rhythm method $(48.3 \%$ vs $3.3 \%$; $p<0.0001)$ and condoms $(19.2 \%$ vs $10.5 \% ; p=0.008)$

(C) The Author(s). 2018 Open Access This article is distributed under the terms of the Creative Commons Attribution 4.0 International License (http://creativecommons.org/licenses/by/4.0/), which permits unrestricted use, distribution, and 
compared to parous women. Hence, OB/GYNs in China should be educated on the safe and effective use of contraceptive methods to guide the general population in choosing the appropriate contraceptive methods.

\section{Background}

Contraceptive use is largely influenced by factors such as access to medical care, social networks, and healthcare providers. OB/GYNs can influence women's choice of contraceptive [1]. The knowledge of OB/GYNs is influential in most women's choice of conceptive methods, as well as in public policies and designing family planning programs $[2,3]$. A previous multinational survey comprising 1001 healthcare professionals (HCPs) reported that the personal choice of contraceptives significantly influenced their recommendations to women [4]. However, it is evident from the literature that there are several misconceptions among $\mathrm{HCPs}$ that contribute to underuse of contraceptives. A study assessing family physicians' perceptions of IUDs revealed that the majority of family physicians believed that pelvic inflammatory disease, ectopic pregnancies, and failure of IUDs were major risks and as a result did not prescribe IUDs [5]. Another study emphasized the need for education and training HCPs about the guidelines for contraceptive use to improve their knowledge and overcome misconceptions [6]. As China accounts for one-fifth of all abortions, there is an unmet need for contraceptive use in avoiding unplanned pregnancies and induced abortions [7]. Thus, the physician's choice may help women select a contraceptive method that best suits their needs and lifestyles, thereby maximizing compliance and helping prevent unintended pregnancies [8]. In addition, China lags behind the rest of the world in the use of oral contraceptives, showing a downward trend in the past two decades from 4.44 to $0.98 \%$ [9]. A pivotal factor impeding women's access to efficient contraceptives may be lack of awareness among Chinese OB/GYNs or the fear of unwanted side effects. Hence, understanding the knowledge and preferences of Chinese OB/GYNs about contraceptive methods is warranted. To date, there is no study on the knowledge of OB/GYNs regarding contraceptive use and determinants influencing contraceptive choices, including emergency methods such as combined oral contraceptives (COCs) and levonorgestrel intrauterine system (LNGIUS). The current study was designed to assess the knowledge and factors influencing the use of contraceptive methods among parous and nulliparous Chinese OB/GYNs.

\section{Methods}

\section{Study design and participants}

This multicenter questionnaire was developed to understand the contraceptive choice of Chinese female $\mathrm{OB} /$
GYNs and their practices on the use of general COCs and LNGIUS used worldwide. Female OB/GYNs participating in training courses on gynecological endocrinology organized by the gynecological endocrinology training committee of the Chinese Medical Doctor Association in multiple regions of China from February to May 2013 participated in the survey with voluntary consent.

The questionnaire was developed at the Peking University People's Hospital, designed to obtain information, including age, height, weight, marital status, cities or areas they are from, grade of hospital and specialty, health conditions, parity, menstruation status, clinically confirmed chronic diseases, choice of contraception, abortion because of unintended pregnancy, and their knowledge about COCs and LNGIUS. The participants were administered paper-based questionnaire. The survey was approved by the Clinical Research Ethics Committee of the Peking University People's Hospital.

\section{Statistical methods}

Data were analyzed using SPSS Statistics version 18.0 (Chicago: SPSS Inc. IBM Corp). Implausible answers and coding errors were carefully reviewed and corrected. The results are presented as counts and percentages. Chi square and ' $t$ ' test was used to compare categorical and continuous data, respectively. A probability value of $<0.05$ was considered to be statistically significant.

\section{Results}

\section{Demographic characteristics of participants}

A total of 2000 questionnaires were distributed. The response rate was $51.4 \%(1027 / 2000)$. All the respondents were involved in clinical work related to contraception, birth control, and/or induced abortion in Class-I (5.8\%), Class-II (42\%), and Class III (52.2\%) hospitals. Majority of the respondents were middle-aged (mean age: $40.0 \pm 9.2$ years). Of the 1027 respondents, 12 (1.2\%) were unmarried and sexually inactive, and the remaining 1015 (98.8\%) were married and sexually active. Majority of the respondents were parous $(83.6 \%, 859 / 1027)$. A total of $197 \mathrm{OB} /$ GYNs had amenorrhea (menopause or total hysterectomy). Of the remaining $830 \mathrm{OB} / \mathrm{GYNs}, 692(83.4 \%)$ reported regular menstrual cycles and 138 (16.6\%) reported irregular cycles. Among the 1015 female OB/GYNs who were sexually active, 571 (56.3\%) had undergone induced abortion because of unintended pregnancy. The reported rate of unintended pregnancies due to an unreliable contraceptive method (rhythm method and lactation amenorrhea) was high at 55.5\%. Other causes for unintended pregnancies were reported failure of reliable contraceptive methods, such as condom slipping or breakage, missing of COCs, and IUD falling out or moving down (18.9\%). Further demographic characteristics of the respondents are given in Table 1. 
Table 1 Demographic characteristics of the respondents

\begin{tabular}{|c|c|}
\hline Characteristics & $\begin{array}{l}\text { Number of } \\
\text { respondents, } n(\%) \\
N=1027\end{array}$ \\
\hline \multicolumn{2}{|l|}{ Age in years } \\
\hline $22-29$ & $126(12.3)$ \\
\hline $30-39$ & $359(35.0)$ \\
\hline $40-49$ & $355(34.6)$ \\
\hline $50-59$ & $137(13.3)$ \\
\hline$\geq 60$ & $50(4.9)$ \\
\hline \multicolumn{2}{|l|}{ Marital status } \\
\hline Married/cohabiting & $1015(98.8)$ \\
\hline Single & $12(1.2)$ \\
\hline \multicolumn{2}{|l|}{ Parity } \\
\hline Parous & 859 (83.6) \\
\hline Nulliparous & $168(16.4)$ \\
\hline \multicolumn{2}{|l|}{ Grade of hospital } \\
\hline 1 & $60(5.8)$ \\
\hline 2 & $431(42.0)$ \\
\hline 3 & $536(52.2)$ \\
\hline \multicolumn{2}{|l|}{ Specialty } \\
\hline Gynecological endocrinology & $77(7.5)$ \\
\hline Gynecology & $465(45.3)$ \\
\hline Obstetrics & $79(7.7)$ \\
\hline Obstetrics and gynecology & $406(39.5)$ \\
\hline \multicolumn{2}{|l|}{ History of clinical confirmed diseases } \\
\hline Hyperlipidemia & $66(6.4)$ \\
\hline Cardiovascular diseases & $36(3.5)$ \\
\hline Diabetes mellitus & $16(1.6)$ \\
\hline Low bone density/osteoporosis & $29(2.8)$ \\
\hline Hyperthyroidism/hypothyroidism & $5(0.6)$ \\
\hline \multicolumn{2}{|l|}{ Menstrual status } \\
\hline $\begin{array}{l}\text { Amenorrhea (menopause and total } \\
\text { hysterectomy) }\end{array}$ & $197(19.1)$ \\
\hline Oligomenorrhea & $72(7)$ \\
\hline Moderate menstrual flow & $648(63.1)$ \\
\hline Menorrhagia & $110(10.6)$ \\
\hline \multicolumn{2}{|l|}{ Reasons for induced abortions } \\
\hline Unreliable contraceptive method & $317(55.5)$ \\
\hline Failure of reliable contraceptive method & $108(18.9)$ \\
\hline $\begin{array}{l}\text { Unintended pregnancy in spite of reliable } \\
\text { contraceptive method }\end{array}$ & $64(11.2)$ \\
\hline Use of emergency contraception & $24(4.2)$ \\
\hline Disease & $5(0.9)$ \\
\hline Medications used during pregnancy & $7(1.2)$ \\
\hline Suspending embryo growth & $3(0.5)$ \\
\hline Abnormal development of fetus & $3(0.5)$ \\
\hline
\end{tabular}

\section{Choice of contraceptive methods}

A total of $367 \mathrm{OB} / \mathrm{GYNs}$ who were sexually active did not use any contraception because of amenorrhea $(n=197 ; 53.67 \%)$ or a plan to conceive $(n=170$; 46.32\%). A total of 516 parous OB/GYNs who had completed their families and 120 nulliparous OB/GYNs who did not plan to conceive at present reported using contraceptive methods. The contraceptive methods used are listed in Table 2. IUDs were the most commonly used method in parous women compared with nulliparous women $(42.6 \%$ vs $1.7 \% ; p<0.0001)$, followed by condom plus rhythm method ( $n=150,24.2 \%$ vs $20.8 \%$ ), condom (used every time, $n=54,10.5 \%)$, and COCs $(n=26,4.4 \%$ vs $2.5 \%)$. On the contrary, the use of rhythm method only $(n=75,48.3 \%$ vs $3.3 \% ; p<0.0001)$ was high among nulliparous women compared with parous women, followed by the use of condoms alone $(n=77,19.2 \%$ vs $10.5 \% ; p=0.008)$. Although IUDs were commonly used in parous women, LNGIUS use remained as low as 1 and $0.8 \%$ in parous and nulliparous women, respectively.

\section{Benefits and side effects of COCs and LNGIUS}

In response to the question of additional benefits, most OB/GYNs reported that COCs are able to relieve dysmenorrhea and premenstrual tension syndrome (73.8\%, $n=758)$; treat polycystic ovary syndrome $(68.1 \%$; $n=699)$; cure acne and improve sebum secretion $(67.95 \%$, $n=697)$; decrease menstrual flow and improve anemia $(64 \%, n=657)$; and reduce the risks of endometriosis, ovarian cancer, and endometrial carcinoma $(61.5 \%, n=632)$. Only $32.8,28.8$, and $28.5 \%$ of the OB/GYNs reported that COCs are able to reduce the incidence rate of pelvic inflammation, cure cutaneous pigmentation, and mitigate melancholia, respectively. Four $\mathrm{OB} / \mathrm{GYNs}$ were unclear about the additional benefits of COCs. Further details regarding the knowledge of $\mathrm{OB} /$ GYNs on clinical application of COCs and side effects are shown in Table 3.

Similarly, majority of the OB/GYNs reported that LNGIUS had additional benefits over a copper IUD in terms of reducing menstrual blood flow and improving menorrhagia and anemia $(81.0 \%, n=831)$; relieving dysmenorrhea $(77.9 \%, n=800)$; protecting uterine endometrium, preventing endometrial hyperplasia, and endometrial carcinoma $(77.0 \%, n=791)$; curing or preventing endometriosis $(59.9 \%, n=615)$; reducing pelvic inflammatory disease risk $(35.1 \%, n=360)$; and reducing the risk of ectopic pregnancy $(0.2 \%, n=2)$.

\section{Discussion}

This survey was the first of its kind to investigate the contraceptive choice of Chinese OB/GYNs. To understand the factors that influence the physician's recommendation of contraceptive methods, it is essential to 
Table 2 Use of contraceptive methods among OB/GYNs or by their partners

\begin{tabular}{|c|c|c|c|}
\hline Method & $\begin{array}{l}\text { Nulliparous, } n(\%) \\
N=120\end{array}$ & $\begin{array}{l}\text { Parous, } n(\%) \\
N=516\end{array}$ & $p$ value \\
\hline Mean age, years & 27.7 & 40.0 & $<0.0001$ \\
\hline IUD & $2(1.7)$ & $220(42.6)$ & $<0.0001$ \\
\hline LNG-IUS & $1(0.8)$ & $5(1.0)$ & 1.000 \\
\hline Condoms & $23(19.2)$ & $54(10.5)$ & 0.008 \\
\hline Condom + rhythm & $25(20.8)$ & $125(24.2)$ & 0.431 \\
\hline Condom + contraception for external use (spermicide) & $7(5.8)$ & $27(5.3)$ & 0.792 \\
\hline $\operatorname{coc}$ & $3(2.5)$ & $23(4.4)$ & 0.392 \\
\hline Long-acting oral contraceptives & $0(0)$ & $3(0.627)$ & - \\
\hline Subdermal implant & $0(0)$ & $2(0.4)$ & - \\
\hline Female sterilization & $0(0)$ & $2(0.4)$ & - \\
\hline Vasectomy & $0(0)$ & $1(0.01)$ & - \\
\hline Coitus interruptus & $1(0.8)$ & $37(7.1)$ & 0.005 \\
\hline Rhythm & $58(48.3)$ & $17(3.3)$ & $<0.0001$ \\
\hline
\end{tabular}

understand the pattern of contraceptive use. A survey on perspectives of HCPs on contraceptive use revealed that misconceptions and lack of knowledge on the long-term effects of contraceptives may have influenced contraceptive counseling and provision [10]. As OB/ GYNs play a major role in counseling and recommendation of contraceptive methods [11], their perceptions and knowledge are of immense importance to meet the unmet needs for contraception and to develop strategies for reducing unintended pregnancies and abortions [12]. The rate of induced abortion because of unintended pregnancy among the OB/GYNs in the present study was as high as $56.3 \%$, which was largely due to the use of unreliable contraceptive methods such as rhythm method and lactation amenorrhea. This was similar to previous studies in Chinese women who reported an absence or poor use of contraceptives as the main cause of unplanned pregnancies, followed by failure of withdrawal, timing, and emergency contraceptive methods [13-15]. In this study, among the OB/GYNs who had completed their families, use of the IUD was high. The proportion of female sterilization $(0.2 \%)$ and vasectomy
(0.1\%) were both low, indicating that $\mathrm{OB} / \mathrm{GYNs}$ preferred reversible methods. Except for the IUD, contraceptive methods of choice were short-acting. Among the 120 nulliparous OB/GYNs, more than half chose unreliable methods. This suggests that OB/GYNs preferred rhythm method and had insufficient knowledge about the high failure rate of condom and rhythm method, which was the leading cause of induced abortion due to unintended pregnancy among female OB/GYNs.

Studies have found that healthcare providers, family physicians, and $\mathrm{OB} / \mathrm{GYNs}$ have inadequate knowledge about contraceptive methods and outdated information about the safety of IUDs $[5,6,16,17]$. The authors agree with these reports, as the use of IUDs was low among nulliparous $\mathrm{OB} / \mathrm{GYNs}$ in the present survey. It may be plausible that the young unmarried $\mathrm{OB} / \mathrm{GYNs}$ were more concerned about the perceived infertility associated with IUDs as they were yet to complete their families unlike the parous OB/GYNs who completed their families. These misconceptions may result from information indicating an inappropriateness of IUDs in nulliparous women as these women have smaller uterus

Table 3 OB/GYNs' knowledge and perceptions of contraceptives clinical application and side effects

\begin{tabular}{|c|c|c|c|}
\hline Questions & Yes, $n(\%)$ & No, $n(\%)$ & Don't Know, n (\%) \\
\hline - Gestational trophoblastic patients may take low dose of COC & $210(20.4)$ & $500(48.7)$ & $317(30.9)$ \\
\hline - Should consider pregnancy 3-6 months after stopping the intake of COC & $252(24.5)$ & $681(66.3)$ & $94(9.2)$ \\
\hline - Taking COC for long term is harmful to health; however, interrupted intake is recommended & $193(18.8)$ & $706(68.7)$ & $128(12.5)$ \\
\hline - Taking COC may reduce the fertility of women & $77(7.5)$ & $822(80.0)$ & $128(12.5)$ \\
\hline - Taking COC for a long term may cause amenorrhea and premature ovarian failure & $109(10.6)$ & $779(75.9)$ & $139(13.5)$ \\
\hline - Taking COC may increase the risk of thrombi formation & $675(65.7)$ & $215(20.9)$ & $137(13.3)$ \\
\hline - Taking COC may increase the risk of breast cancer & $381(37.1)$ & $466(45.4)$ & $180(17.5)$ \\
\hline - Taking COC may cause weight gain & $511(49.8)$ & $376(36.6)$ & $140(13.6)$ \\
\hline
\end{tabular}


that might increase the expulsion rate and increase the pain with insertion [18]. Similar to this study, previous studies from Western countries have reported a lack of awareness and misconceptions among HCPs regarding the unsuitability of IUD in certain groups of women, levying a substantial impact on the IUD use [19]. In addition, LNGIUS use in this study was low (0.5\%), despite its availability in the Chinese market since 2000 and high satisfaction rates among Chinese women [20]. The reason for the low prevalence may be the high price, which is not covered under the health insurance schemes. However, OB/GYNs demonstrated knowledge of non-contraceptive therapeutic actions and benefits of LNGIUS.

In this study, a high proportion of female OB/GYNs had misconceptions about the clinical application of COCs, such as reduced fertility, harmful long-term effects, amenorrhea and premature ovarian failure, increased risk of breast cancer, and weight gain. With various continuing education programs in the recent years, knowledge of OB/GYNs on reproductive safety of COCs has improved; $66.3 \%$ of the respondents reported that it is good to get pregnant after discontinuing COCs. However, concern about the side effects of COCs may lead to decreased use of COCs among OB/GYNs. In addition, this concern may influence $\mathrm{COC}$ use among the general population. Another reason for low $\mathrm{COC}$ use might be the preference toward long-acting contraceptive methods in the family planning policy. This perception is in concordance with previous findings that women were unlikely to prefer everyday pills because of the concern of side effects and hazard to overall health [21-23]. Although COCs are not the preferred choice of contraception among female OB/GYNs in this study, they are highly recognized as rendering benefits other than contraception, such as treating dysmenorrhea, relieving premenstrual tension, treating acne and improving sebum secretion, reducing menstrual flow and improving anemia, treating endometriosis, and decreasing the risks of ovarian cancer and/or endometrial carcinoma.

Overall, we observed that most OB/GYNs preferred long-acting, reversible, cost-effective contraceptives with least side effects. According to previous studies, these factors influenced HCP recommendation of contraceptives [4].

This study has several limitations. The main limitation was that the questionnaire was exclusively designed for $\mathrm{OB} / \mathrm{GYNs}$ and was not intended to evaluate the contraceptive recommendation given by them to their patients. In addition, the survey was conducted in 2013 and involved only OB/GYNs from urban areas, which may lead to selection bias and non-generalizability of the findings to OB/GYNs in rural areas of China. Also, the questionnaire was exhaustive and some respondents found it too cumbersome to complete. The survey findings reveal the lacunae in the knowledge and perceptions of the $\mathrm{OB} /$ GYNs on contraceptive choice and use. This warrants caution and a need to provide effective education about the safe and effective use of contraceptive methods to $\mathrm{OB} / \mathrm{GYNs}$ to reduce the rate of unintended pregnancies in the rest of the population in China.

\section{Conclusions}

In summary, the high rate of induced abortion among OB/GYNs in urban China may be influenced by the use of unreliable contraceptive methods, which is due to misconceptions regarding reliable methods such as COCs and LNGIUS. In addition, the use of IUDs was dependent on the perceptions based on parity of the individual OB/GYN, wherein the nulliparous $\mathrm{OB} / \mathrm{GYNs}$ were unlikely to use IUDs because of perceived infertility in the future. Hence, continuous education about the safe and effective use of contraceptive methods should be strengthened among OB/GYNs to overcome the misconceptions and fear of side effects to ensure the unbiased recommendation of contraceptive methods to the general public.

\section{Abbreviations \\ COC: Combined oral contraceptive; HCP: Healthcare professional; IUD: Intrauterine device; LNGIUS: Levonorgestrel intrauterine system; OB/GYN: Obstetrician/Gynecologist}

\section{Acknowledgments}

The authors gratefully acknowledge Guanghuachu, PhD, and Professor Shangchun Wu (National Research Institute for Family Planning, Beijing) for statistical support. They also thank Navya, Dr. Anuradha Nalli, and Dr. Amit Bhat (Indegene, Bangalore) for providing medical writing assistance for this manuscript.

\section{Funding}

This study was funded by the key project of National Twelfth Five-Year Plan for Science and Technology Support: Evaluation of reproductive health and menopausal health condition (Project no. 2012 BAI32B00).

Availability of data and materials

All data are included in the manuscript. Additional data can be obtained from the corresponding author of the manuscript.

\section{Authors' contributions}

$X Y, X L, Y W, X H$, and $Y Z$ planned and contributed to the interpretation of the data, revisions, and inputs at all stages of the study. All the authors have approved the final version of the manuscript.

\section{Ethical approval and consent to participate}

The survey was approved by the Clinical Research Ethics Committee of the Peking University People's Hospital. A written consent was obtained from all participants of the survey.

\section{Consent for publication}

All authors reviewed the final draft and have given their consent for publication of the survey results.

Competing interests

The authors declare that they have no competing interests. 


\section{Publisher's Note}

Springer Nature remains neutral with regard to jurisdictional claims in published maps and institutional affiliations.

\section{Author details}

'Department of Obstetrics and Gynecology, Peking University People's Hospital, Xicheng District, Beijing 100044, China. ${ }^{2}$ Department of Obstetrics and Gynecology, The Second Hospital of Hebei Medical University, Xinhua District, Beijing, Hebei Province, China.

Received: 10 January 2017 Accepted: 14 June 2018

Published online: 26 June 2018

\section{References}

1. Yee $L$, Simon M. The role of the social network in contraceptive decisionmaking among young, African American and Latina women. J Adolesc Health Off Publ Soc Adolesc Med. 2010;47:374-80.

2. Li J, Temmerman M, Chen Q, Xu J, Hu L, Zhang W-H. A review of contraceptive practices among married and unmarried women in China from 1982 to 2010. Eur J Contracept Reprod Health Care Off J Eur Soc Contracept. 2013;18:148-58.

3. Sevey Lawrence. Physicians' perceptions of contraceptive methods: cultural comparisons [internet]. The east-west population institute East-West Center Honolulu, Hawaii; Available from: http://pdf.usaid.gov/pdf_docs/Pnabd098. pdf.

4. Gemzell-Danielsson K, Cho S, Inki P, Mansour D, Reid R, Bahamondes L. Use of contraceptive methods and contraceptive recommendations among health care providers actively involved in contraceptive counseling results of an international survey in 10 countries. Contraception. 2012;86:631-8

5. Stubbs E, Schamp A. The evidence is in. Why are IUDs still out?: family physicians' perceptions of risk and indications. Can Fam Physician Med Fam Can. 2008:54:560-6.

6. Harper CC, Blum M, de Bocanegra HT, Darney PD, Speidel JJ, Policar M, et al Challenges in translating evidence to practice: the provision of intrauterine contraception. Obstet Gynecol. 2008;111:1359-69.

7. Sedgh G, Henshaw S, Singh S, Åhman E, Shah $1 \mathrm{H}$. Induced abortion: estimated rates and trends worldwide. Lancet. 2007;370:1338-45.

8. Teutsch C. Patient-doctor communication. Med Clin North Am. 2003:87: 1115-45.

9. Wang C. Trends in contraceptive use and determinants of choice in China: 1980-2010. Contraception. 2012;85:570-9.

10. Nalwadda G, Mirembe F, Tumwesigye NM, Byamugisha J, Faxelid E. Constraints and prospects for contraceptive service provision to young people in Uganda: providers' perspectives. BMC Health Serv Res. 2011; 11:220.

11. Forrest JD, Frost JJ. The family planning attitudes and experiences of lowincome women. Fam Plan Perspect. 1996;28:246-55. 277

12. Adding It Up: Investing in Contraception and Maternal and Newborn Health, 2017 [Internet]. Guttmacher Institute; Available from: https://www. guttmacher.org/fact-sheet/adding-it-up-contraception-mnh-2017.

13. Cheng $Y, X u X, X u$ J, Wuillaume F, Zhu J, Gibson D, et al. The need for integrating family planning and postabortion care in China. Int J Gynaecol Obstet Off Organ Int Fed Gynaecol Obstet. 2008;103:140-3.

14. Luo Z-Y, Quan S, Chai D-N, Zhang W-H. Cohort records study of 19,655 women who received Postabortion Care in a Tertiary Hospital 2010-2013 in China: what trends can be observed? Biomed Res Int. 2016;2016:1-5.

15. Huang Y-M, Merkatz R, Kang J-Z, Roberts K, Hu X-Y, Di Donato F, et al. Postpartum unintended pregnancy and contraception practice among rural-to-urban migrant women in shanghai. Contraception. 2012;86:731-8.

16. Dehlendorf C, Levy K, Ruskin R, Steinauer J. Health care providers' knowledge about contraceptive evidence: a barrier to quality family planning care? Contraception. 2010;81:292-8.

17. Schreiber CA, Harwood BJ, Switzer GE, Creinin MD, Reeves MF, Ness RB. Training and attitudes about contraceptive management across primary care specialties: a survey of graduating residents. Contraception. 2006;73:618-22.

18. Beatty MN, Blumenthal PD. The levonorgestrel-releasing intrauterine system: safety, efficacy, and patient acceptability. Ther Clin Risk Manag. 2009:5:561-74
19. Buhling KJ, Zite NB, Lotke P, Black K. INTRA writing group. Worldwide use of intrauterine contraception: a review. Contraception. 2014:89:162-73.

20. Zhao S, Deng J, Wang Y, Bi S, Wang X, Qin W, et al. Experience and levels of satisfaction with the levonorgestrel-releasing intrauterine system in China: a prospective multicenter survey. Patient Prefer Adherence. 2014;8:1449-55.

21. Rosenberg MJ, Burnhill MS, Waugh MS, Grimes DA, Hillard PJ. Compliance and oral contraceptives: a review. Contraception. 1995;52:137-41.

22. Rosenberg MJ, Waugh MS, Burnhill MS. Compliance, counseling and satisfaction with oral contraceptives: a prospective evaluation. Fam Plan Perspect. 1998;30:89-92. 104

23. Rosenberg MJ, Waugh MS. Oral contraceptive discontinuation: a prospective evaluation of frequency and reasons. Am J Obstet Gynecol. 1998;179:577-82.

\section{Ready to submit your research? Choose BMC and benefit from:}

- fast, convenient online submission

- thorough peer review by experienced researchers in your field

- rapid publication on acceptance

- support for research data, including large and complex data types

- gold Open Access which fosters wider collaboration and increased citations

- maximum visibility for your research: over $100 \mathrm{M}$ website views per year

At BMC, research is always in progress.

Learn more biomedcentral.com/submissions 